\title{
COMPUTER AIDED SIMULATION FOR NON-LINEAR MODEL OF SHIP MOTION
}

\author{
NGUYEN NHAT LE
}

SUMMARY. The ship motion is simulated on computer by non-linear model of small vibration and strong non-linear model. The results are compared between two models. The influences of different parameters to the ship motion are considered.

\section{§1. INTRODUCTION}

The non-linear model simulation of ship motion has been studied by Nguyen Van Dao [1]. proposed model consists of a mass $M$ restrained by a non-linear elastic spring and a mass $m$ ched to a hinged, weightless rod (Fig. 1). This system has the vertical and angular oscillations.

\section{§2. SIMULATION FOR NON-LINEAR MODEL OF SMALL VIBRATION}

The differential equations of motion for the system represented in Fig. 1 are writen as follows

$$
\begin{aligned}
& (M+m)(\ddot{Z}+\ddot{u})+k_{0} Z+\beta_{0} Z^{3}+h_{0} \dot{Z}+m \ell\left(\ddot{\varphi} \sin \varphi+\dot{\varphi}^{2} \cos \varphi\right)=0 \\
& m \ell^{2} \ddot{\varphi}+C_{0} \dot{\varphi}+m \ell(g+\ddot{Z}+\ddot{u}) \sin \varphi=0
\end{aligned}
$$

ce $Z=x-u$ is the relative vertical displacement of the mass $M ; x$ is the vertical displacement te mass $M$ from its static position of equilibrium; $u=q \cos \omega t$ is the vertical displacement of base of the system; $\varphi$ is the angular displacement of the pendulum; $k_{0}$ and $\beta_{0}$ are the linear non-linear characteristics of the spring, respectively; $h_{0}$ and $C_{0}$ are the damping coefficients .e vertical and angular motions, respectively.

Supposing that the damping forces and the ratios $\sigma=q / \ell ; \mu=m /(M+m)$ are small, the rential equations of small vibrations are written as follows [1]:

$$
\begin{aligned}
W^{\prime \prime}+k^{2} W & =-\varepsilon\left[-\sigma \eta^{2} \cos \eta \tau+h W^{\prime}+\beta W^{3}+\mu\left(\varphi \varphi^{\prime \prime}+\varphi^{\prime 2}\right)\right]+\varepsilon^{2} \ldots \\
\varphi^{\prime \prime}+\varphi & =\varepsilon\left[-C \varphi^{\prime}+\frac{\varphi^{3}}{6}-\varphi W^{\prime \prime}+\sigma \eta^{2} \varphi \cos \eta \tau\right]+\varepsilon^{2} \ldots
\end{aligned}
$$




$$
\begin{aligned}
W & =\frac{Z}{\ell} ; \quad \eta=\frac{\omega}{\omega_{0}} ; \quad \omega_{0}=\sqrt{\frac{g}{\ell}} ; \quad C=\frac{C_{0}}{\omega_{0} m \ell^{2}} \\
h & =\frac{h_{0}}{\omega_{0}(M+m)} ; \quad k^{2}=\frac{k_{0}}{\omega_{0}^{2}(M+m)} ; \quad \beta=\frac{\beta_{0} \ell^{2}}{\omega_{0}^{2}(M+m)} \\
\mu & =\frac{m}{(M+m)} ; \quad \sigma=\frac{q}{\ell} ; \quad \tau=\omega_{0} t .
\end{aligned}
$$

Computer aided simulation for differential equations of small vibrations (2.2) with the different data in [1] with:

$$
\mu=0.05 ; \quad k=2 ; \quad h=C=0.10 ; \quad \sigma=4.5 \cdot 10^{-2} ; \quad \beta=0 \text { and } \beta=1
$$

we obtain the behaviours of $\varphi(t)$ and $W(t)$ as shown in Fig. 2. Where $\varphi(\tau)$ : damped vibration, $W(\tau)$ : periodic vibration affter a time.

The change of coefficient $\beta(\beta=0$ or $\beta=1)$ and the change of coefficient $\eta$ have a very small influence to the motions.

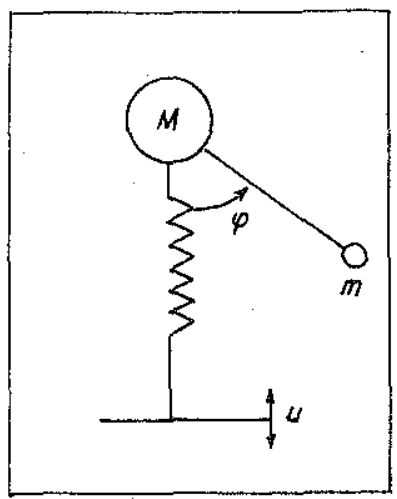

Fig. 1

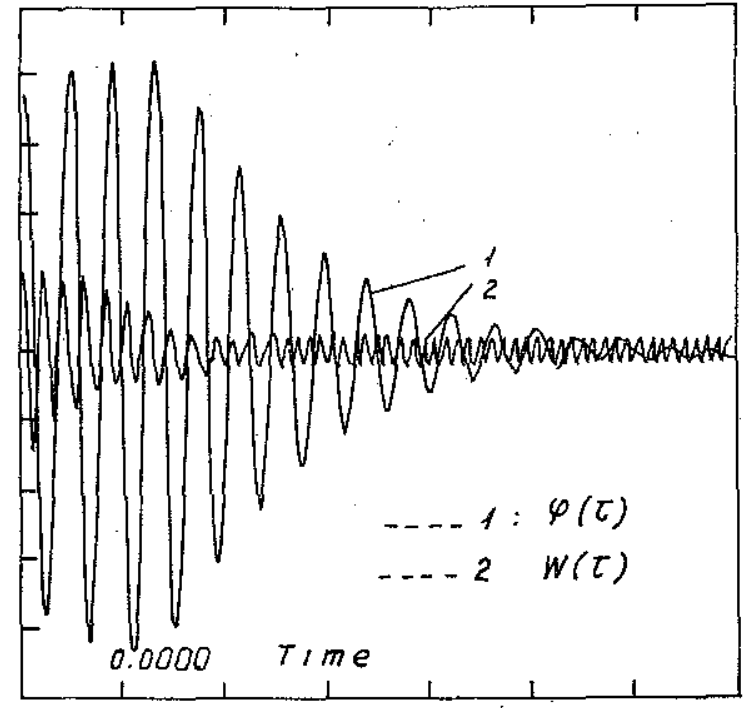

Fig. 2

\section{§3. SIMULATION FOR STRONG NON-LINEAR MODEL}

For general strong non-linear model of ship motion, the differential equations of motion has the form (2.1). This form has been studied by means of the asymptotic method of non-linear mechanics [1]. It is can be simulated on computer as shown in Fig. 3:

With this computer aided simulation we can observe all motions corresponding to the different real parameters.

1. Influence of the non-linear damping coefficients:

Making change the non-linear damping coefficients, we see that the term $\beta_{0}$ in the non-linear characteristic of the spring has a very small influence to the vertical motion, while the damping term $C_{0}$ of the angular motion has a considerable influence to this motion.

2. Influence of the length of the rod:

Taking the ratios 


$$
\mu=\frac{m}{(M+m)}=0.05 ; \quad \sigma=\frac{q}{\ell}=0.045 ; \quad \eta=\frac{\omega}{\omega_{0}}=1.8
$$

the change of $q$ and $\ell$ has a influence to the behaviours of motions.

- with $\ell=2.2, q=0.1$ : The response curves of displacements $Z$ and $\varphi$ are ploted in Fig. 4

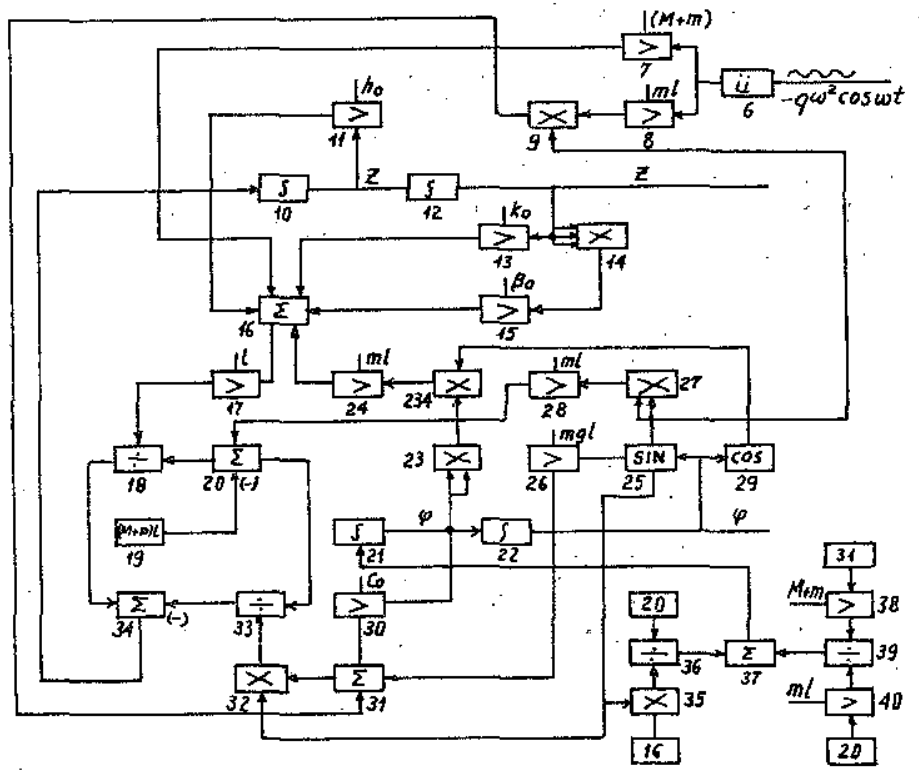

Fig. 9

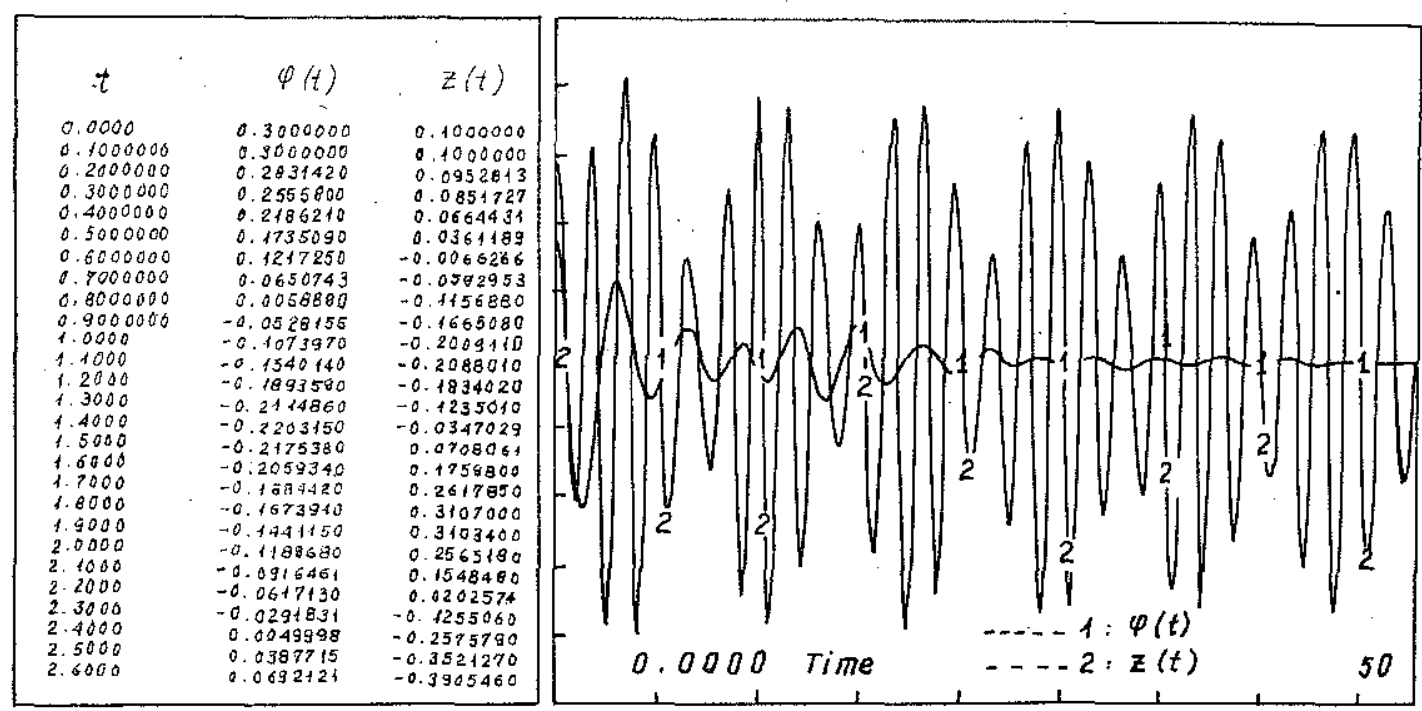

Fig. 4

Where, the angular displacement $\varphi$ is damped, while the vertical displacement $Z$ has a beat phenomenon.

Thus, corresponding with the observation in [1], for the case considered this is only the purely vertical motion. 
- with $\ell=1 ; q=0.045$; the shape of the response curves and the coupling between $\varphi$ and $Z$ are shown in Fig. 5. Where, both the behaviours $\varphi(t)$ and $Z(t)$ have the beat phenomenon.

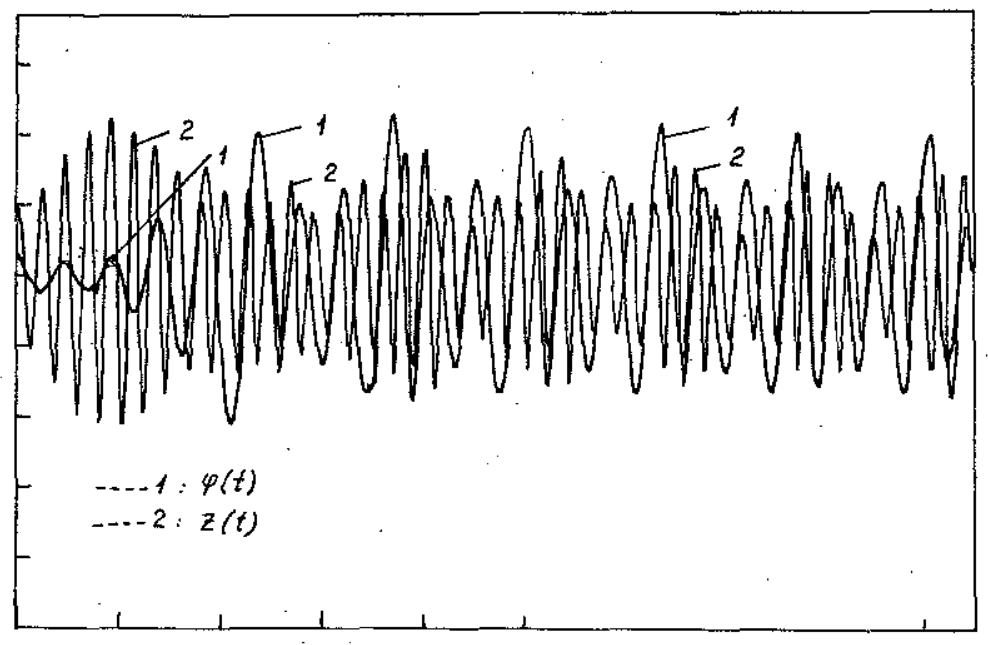

Fig. 5

3. Coupling between vertical and angular motions:

The coefficient $\eta=\omega / \omega_{0}$ has a essential influence on the coupling between vertical and angular motions. However the coupling between two displacements $\varphi$ and $Z$ is small with

$$
1.65 \leq \eta<2
$$

where $\varphi(t)$ is damping oscillation, $Z(t)$ has the beat phenomenon.

Its behaviours are analogous with those in Fig. 4.

The coupling strongly occurs in the resonant regions, i.e.

$$
2=\eta \leq 2.12
$$

The coupling at the resonance $(\eta=2)$ is ploted in Fig. 6 .

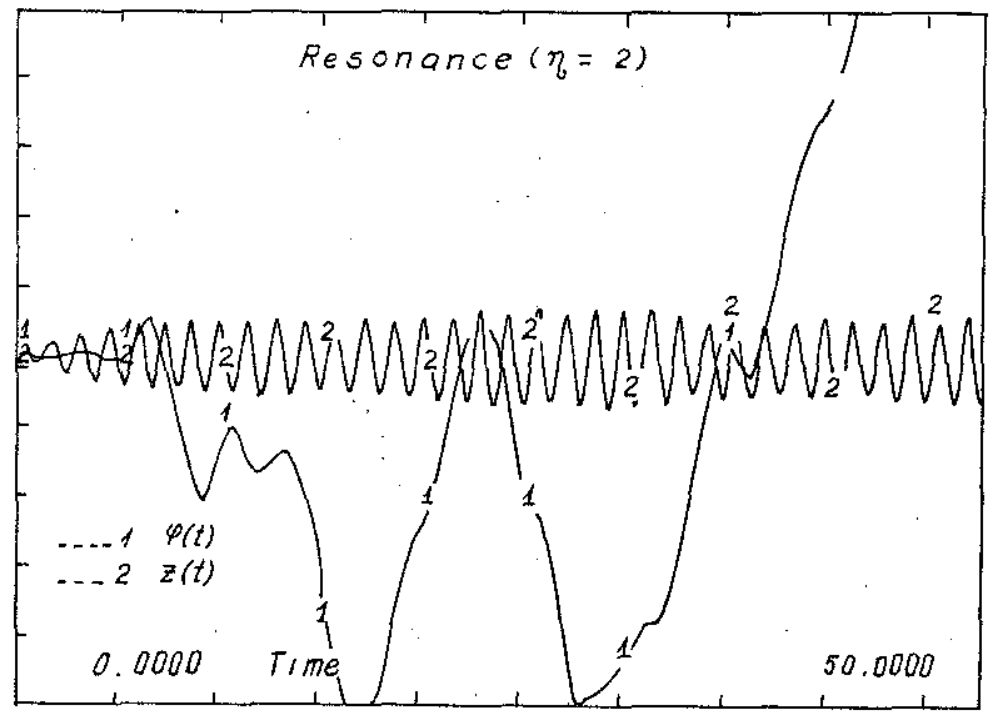

Fig. 6 
With $\eta \geq 2.5$, the shape of the response curves is analogous with that in Fig. 5 .

4. Others influence of the parameters:

Making change others parameters of the different blocs in the flow diagram on Fig. 3 we can see on computer screen the direct displays of different motions considered.

Basing on the study in $[1]$ and the computer aided simulation we can observe others phenomenons occured by the strong non-linearity of the system (2.1). Also, we can select the convenient paraneters to occur the desirous motions.

\section{CONCLUSION}

The ship motion is simulated on computer by two models of small vibration and of strong non-linearity.

The influences of different parameters are considered and compared. The experimental results are in accordance with theoretical ones [1]. With this computer aided simulation we can select the reel parameters to find the convenient motions.

This publication is completed with financial support from the National Basic Research Program in Natural Sciences.

\section{REFERENCES}

1. Nguyen Van Dao. Non-linear model simulation of ship motion. Journal of Mechanics, T. XIV, No 2, 1992.

Received May S, 1998

\section{MÔ PHỎNG TRÊN MÁY VI TÍNH MÔ HİNH PHI TUYẾN CỦA CHUYỂN ĐộNG TÀU THƯY}

Mô hình phi tuyến yếu cho dao động lắc ngang và thẳng đứng của tàu thủy đã được nghiên cứu băng phương pháp tiệm cận cưa dao động phi tuyến [1].

Trong bài này, mô hình phi tuyến trên đã được mô phỏng trên máy tính, với hai mô hình: dao động bé và phi tuyến mạnh. Đã xét ành hướng của các thông số đến dáng điệu của chuyển động. Với sự mô phóng này, chúng ta có thể dễ dàng thay dổi các tham số và quan sát trực tiếp trên màn hình các dạng chuyển động đồng thời thăng đúng và lăc ngang cưa tàu. 